\title{
REPRODUCTIVE PERFORMANCE ON THE MALTESE ISLANDS DURING THE SECOND WORLD WAR
}

\author{
by \\ C. SAVONA-VENTURA *
}

The Maltese Islands are a group of small islands in the central Mediterranean, of which two are inhabited. Malta had a population in 1938 of 242,885, and Gozo then had 25,783 inhabitants. The islands are small: the largest Malta, is 94.87 square miles in area, and Gozo, 26.97 square miles. ${ }^{1}$ The islands were not occupied during the Second World War, but they were subjected to ferocious bombings and the inevitable deprivations that resulted from their isolated position. War affects the reproductive performance of a population; changes are reflected in the maternal, infant, and neonatal mortality rates, the birth rates, and still-birth rates. The experience of the Maltese Islands provides some valuable insights.

After Germany invaded Poland, Great Britain and France mobilized on 1 September 1939. Following the declaration of war, Malta-a British colony-quickly prepared for war. Hostilities there began officially on 11 June 1940 after Benito Mussolini declared war on the Allies. Five hours later, the Maltese Islands suffered an air raid, in the first of eight raids over the next 24 hours. The islands were bombed regularly after that with an increasing tempo. Hostilities on the islands subsided in November 1942 after the Allied offensive opened in Egypt and General Erwin Rommel's army retreated. ${ }^{2}$ According to the official statistics, throughout this period of about 900 days there were 2,537 alerts, with 492 day raids and 574 night raids. The total tonnage of bombs dropped on the islands during March and April 1942 alone was twice that dropped on London during the years of its worst attacks. ${ }^{3}$

The blockade enforced by the Axis control of the Mediterranean supply lines had considerable effects. Malta had never been self-supporting and Sicily, its nearest neighbour, had provided much of the islands' imports. On the outbreak of the war, these supplies were abruptly cut off and the islands' supplies were maintained, with varying success, through 1940 and 1941 by Royal Navy and Merchant Marine

*C. Savona-Ventura, MD, MRCOG, Department of Obstetrics and Gynaecology, St Luke's Hospital, G'mangia, Malta.

${ }^{1}$ Annual report on the health conditions of the Maltese Islands and on the work of the Medical and Health Department for the year 1938, Malta Government Gazette Suppl. 154, Malta, Govn. Printing Office, December 1939, p. 5.

${ }^{2}$ F. S. De Domenico, An island beleaguered, Malta, Giov. Muscat Press, 1946, pp. 19-22, $179-9$.

${ }^{3}$ P. Shankland and A. Hunter, Malta convoy, London, Collins, 1961, p. 60, and De Domenico, op. cit., note 2 above, p. 144. 
convoys. Food throughout these two years was rationed and often in short supply, but no great hardship was experienced. On 25 January 1942 the airfields of Cyrenaica, which had provided fighter cover to the supply ships, fell into enemy hands, increasing further the islands' isolation. ${ }^{4}$ Food became scarcer and by August 1942 the islands were within a few days of starvation. ${ }^{5}$ The situation improved slightly after a convoy broke through on 12 August 1942, but food shortages continued until after November 1942.

The onset of hostilities on the islands found the Medical and Health Department prepared. War curtailed the construction of St Luke's Hospital on Malta, and the Emergency Services thus required a number of temporary hospitals to allow for the increased demands expected during war-time. The Central Hospital, on Malta, at the time was overcrowded with an average daily population of about 300 patients. $^{6}$ Throughout 1939, the Department of Health, under the directorship of the Chief Government Medical Officer Dr A. V. Bernard, had been revising the scheme for the establishment of casualty hospitals and other emergency services, collecting reserve stores, recruiting and training staff, and making all the necessary preparations for war. By September 1939, the Department was ready to provide 1,200 to 1,500 beds for casualties, as well as a 100-bed maternity hospital, and special wards for cases of war neurosis. The mobilization of the Emergency Services was started, but the complete scheme was not put into operation until the outbreak of hostilities with Italy. ${ }^{7}$ The medical-supplies reserve was markedly augmented when the scheme for the Emergency Medical Services was drawn up, and during the war some drugs and other medical requisites were brought in. The supplies dwindled to very low levels, but never to an alarming extent. ${ }^{8}$ The war brought on serious health problems, not only from war casualties and poor nutrition, but also from sanitary problems in the dormitory shelters, as people moved from heavily bombed areas to refugee areas

\footnotetext{
${ }^{4}$ Shankland and Hunter, op. cit., note 3 above, pp. 47-8.

${ }^{5}$ Report on the health conditions of the Maltese Islands and on the work of the Medical and Health Department including the Emergency Medical Services for the year 1942, Malta, Govn. Printing Office, 1943, p. 1. "After the period of continuous attacks, the people had to endure for the rest of the year severe restrictions due to the acute siege conditions that ensued. Food rations, as well as allowances of water, soap, fuel and other necessaries had to be progressively curtailed. The calorie value of the diet became dangerously low and the protective constituents-fresh meat, eggs, milk, butter-were practically unobtainable for a considerable time. The people had to subsist mostly on vegetable soup, some tinned meat or fish, a little fat and oil and beans. The fresh meat available, a good proportion being goat or horse, was reserved for the hospitals and all milk strictly rationed to people who were seriously ill."

${ }^{6}$ Annual report on the health conditions of the Maltese Islands and on the work of the Medical and Health Department for the year 1939, Malta, Govn. Printing Office, 1940, p. 2. The patient population at the Central Hospital was 310 in 1937, 289 in 1938, and 273 in 1939.

${ }^{7}$ Ibid., p. 2.

8 Report ... 1942, op. cit., note 5, p. 1. "Baby and invalid foods were unobtainable and the reserves of medical supplies dwindled to very low levels. A certain amount of drugs, disinfectants and other medical requisites were brought in by bomber, submarine and other special means. By the exercise of strict economy in all things we were able not only to carry on the work of the hospitals but also to supply private chemists with the more essential drugs. Luckily we had laid in a substantial reserve of medical stores when the scheme for the emergency medical services was drawn up in 1935 and without this reserve we would not probably have successfully withstood the siege." In 1935 Italy invaded Abyssinia, and the Leage of Nations branded Italy as an aggressor and imposed limited sanctions. The threat of war between Italy and Britain initiated these protective measures.
} 


\section{Savona-Ventura}

ill-equipped to serve their needs. These problems affected, among other things, the reproductive performance of the population and necessitated changes in the obstetric services.

\section{BIRTH-RATE CHANGES}

Before the war, most births on the islands were domiciliary with midwife assistance, doctors being called in when problems occurred in delivery. Referral to the hospital was often a late event. ${ }^{9}$ In a district-based midwifery system, Malta was divided into twelve districts and Gozo into four. Government subsidies were given to needy mothers. ${ }^{10}$ The Central Hospital on Malta, with only 16 beds reserved for obstetric cases, accounted in 1938 for only 4.3 per cent of the total births in Malta; Victoria Hospital on Gozo, with 10 lying-in beds, accounted for 22.2 per cent of the births on that island. ${ }^{11}$ Normal services continued up to May 1940, when an Emergency Maternity Hospital was opened on Malta, increasing the number of maternity beds to $100 .{ }^{12}$ The hospital confinement rate increased on Malta during the war years, reaching a maximum of $14 \cdot 1$ per cent total Maltese births in 1941 (table 1). On Gozo, the situation remained unaltered. During 1941 , the district maternity services were expanded by the establishment in many villages of maternity cubicles in bomb-proof shelters for women who preferred to remain near their homes rather than go to hospital. ${ }^{13}$

The birth rate of the Maltese Islands prior to 1939 varied little, fluctuating around a mean of 33.26 per 1,000 population since 1930. The rate was higher in Malta (32.79) than on Gozo (28.62) with a live-birth ratio between Malta and Gozo of 10.8 in 1938. The onset of the war in mid-1940 had very little effect on the birth rate of that year, which was 32.53 per 1,000 population overall. A slight lowering of the live-birth ratio between Malta and Gozo to $10 \cdot 3$ resulted from the mass migration of families from Malta to the less vulnerable island Gozo, whose estimated population density increased from 971.0 per square mile, in 1939 , to 1086.0 in $1940 .{ }^{14}$ In 1941 , the birth rate on both islands dropped markedly, to 27.39 per 1,000 population on Malta and 25.02 on Gozo. The live-birth ratio between Malta and Gozo fell further, to 9.0,

\footnotetext{
9 Annual Report ... 1938, op. cit., note 1 above, p. 106.

${ }^{10}$ Ibid., p. 9.

${ }^{11}$ Ibid., pp. 28-9, 93-4, 142. The visiting medical staff at the Central Hospital on Malta consisted of two accouchers and gynaecologists. The Senior Accoucher/Gynaecologist was Professor J. Ellul, while the Junior Accoucher/Gynaecologist was Dr V. Stillon. The medical staff at the Victoria Hospital at Gozo consisted of a non-resident Physician, Surgeon, and Superintendent, and a Resident Assistant Medical Officer.

12 Annual report on the health conditions of the Maltese Islands and on the work of the Medical and Health Department including the Emergency Medical Services for the year 1940, Malta, Govn. Printing Office, 1941, pp. 10-11, 29. An Emergency Maternity Hospital was opened at Hamrun (Malta) in a newlyconstructed wing of the Adelaide Cini Orphanage, increasing the number of maternity beds to 100 . The maternity services were transferred initially on 28 May 1940 to the Bugeja Technical Institute and eventually on 19 June to the nearby Cini Orphanage.

${ }^{13}$ Report on the health conditions of the Maltese Islands and on the work of the Medical and Health Department including the Emergency Medical Services for the year 1941, Malta, Govn. Printing Office, 1943, pp. 2, 25. A convenient part of a rock shelter was specially equipped and set apart for the confinement of mothers. They were allowed to come in a few days before confinement was expected and to remain for about a week after the event.

${ }^{14}$ Annual report ... 1939, op. cit., note 6 above, p. 4 and Annual report ... 1940, op. cit., note 12 above, p. 6.
} 


\section{Reproductive performance on the Maltese Islands}

Table 1: OBSTETRIC SERVICES ON THE MALTESE ISLANDS, 1938-44

Year District subsidies Hospital statistics ${ }^{1}$

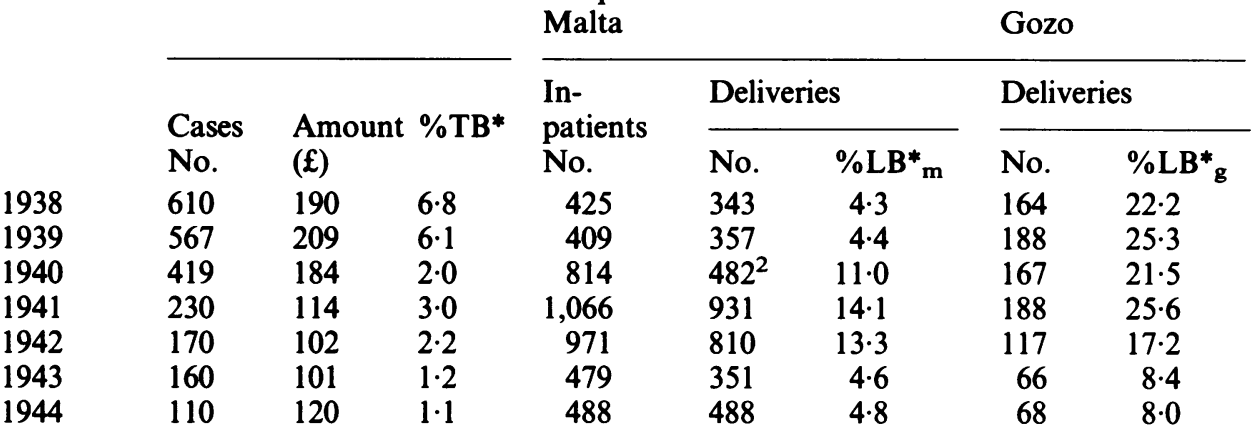

* \% TB percent total births; \%LB percent live births Malta/Gozo

1 In Malta, Central Hospital until May 1940, subsequently Cini Hospital. In Gozo, Victoria Hospital.

2 Number of deliveries for June-December 1940, rate per cent live births in Malta corrected for same months. Number of in-patients total for January-December 1940 (June-December $1940=637$ ).

indicating a proportionately higher number of births on Gozo. The birth rate continued to fall in 1942. The cessation of hostilities at the end of 1942 showed its effects the following year, with a rise in the birth rate to 31.06 per 1,000 population in 1943 , and a further rise, to $39 \cdot 26$, in 1944 . While the rise in the birth rate during these two years occurred on both Malta and Gozo, the post-war surge was most marked on Malta, where it reached a peak of 40.54 per 1,000 population in 1944 . This rise continued until 1950, after which the birth rate reached pre-war levels and subsequently fell further (figure 1). In the post-war years there was a marked decrease in the number of patients using the institutionalized maternity services, a situation that continued in subsequent years (table 1). Early in 1944, partial demobilization of the Emergency Medical Services was carried out, but the Emergency Maternity Hospital continued to function until 1949 when St Luke's Hospital was completed on Malta. ${ }^{15}$

The sudden and marked diminution in the birth rate during the war is not surprising in view of the marked disturbance to family life brought on by the war. Communal living, with one and even more families living in a single room, and the conglomeration of families in the dormitory shelters necessitated by the continuous air attacks and the destruction of dwellings, were the most important factors in determining the lowered natality. The same factors were also responsible for the increase in the hospital-confinement rate on Malta during the war. ${ }^{16}$ The calling up of a large number of men to the services may also have contributed to the lowered birth rate, though the marriage rate in 1941 ( $8 \cdot 2$ per 1,000 population) was actually higher

\footnotetext{
${ }^{15}$ Report on the health conditions of the Maltese Islands and on the work of the Medical and Health Department for the year 1949, Malta, Govn. Printing Office, 1950. The project of St Luke's Hospital at Gwardamangia (Malta) was initiated in 1930 and the hospital, aimed to have about 510 beds, had been planned for completion in 1941. The onset of the war curtailed the construction work. The Maternity Division was transferred from Cini Hospital in September 1949.

${ }^{16}$ Annual reports on the health conditions of the Maltese Islands and on the work of the Medical and Health Department, including the Emergency Medical Services for the years 1926, 1936-1952, 18 vols., Malta, Govn. Printing Office, 1927, 1937-1954.
} 


\section{Savona-Ventura}

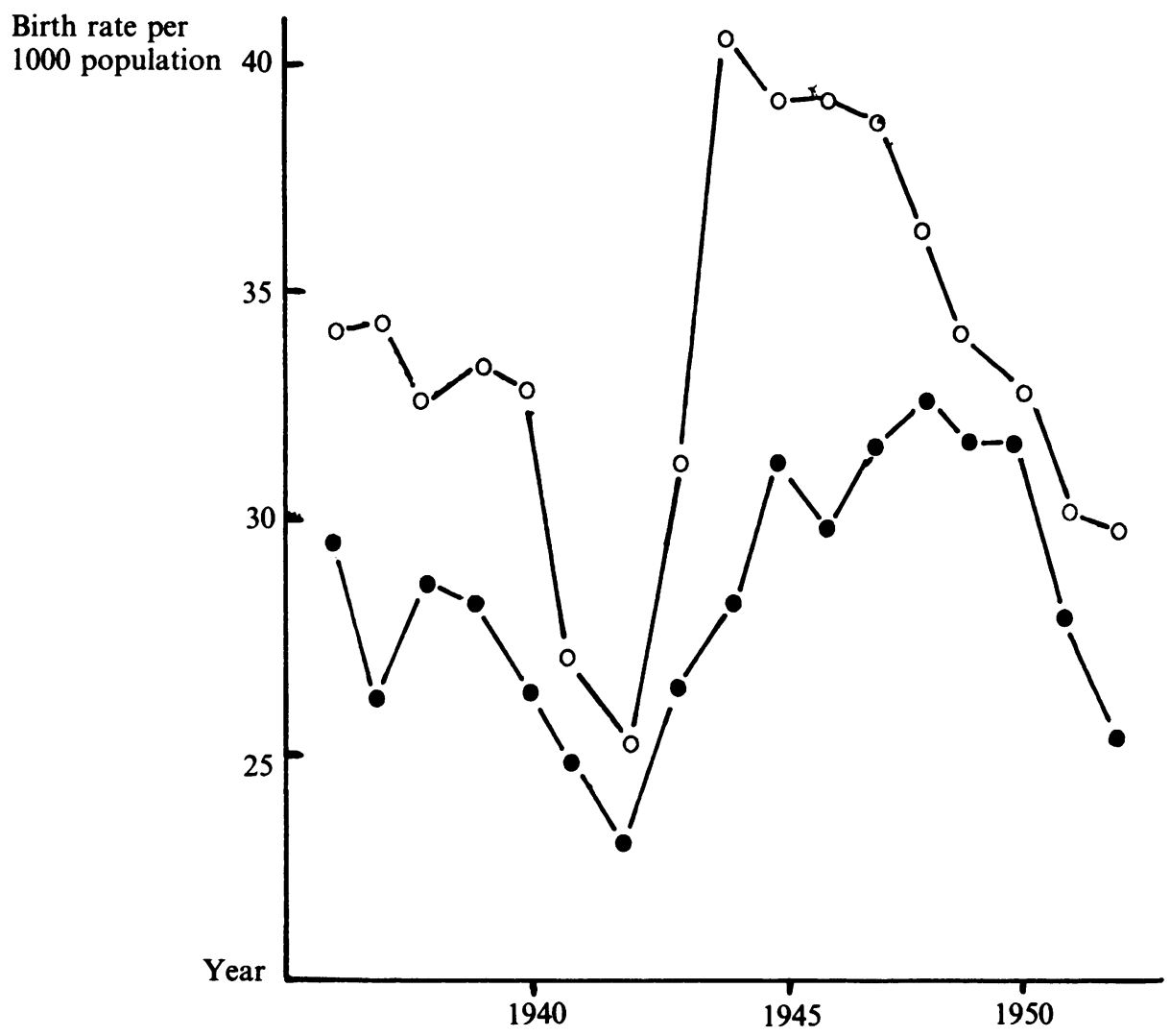

Figure 1: Birth rates on Malta and Gozo, 1936-52 ( $-\circ$ Malta; $-\bullet$ Gozo).

than pre-war rates (7.3 in 1939). Conscription on Malta was introduced early in 1941. Conscripts were not forced to serve outside Malta, though they could volunteer for foreign service if they wished. Reluctance to conceive in war conditions may have encouraged birth control. ${ }^{17}$ The poor nutrition of the population resulting from the blockade may also have interfered with reproduction. The fact that, with the resumption of semi-normal life by 1943, the birth rate returned to near-normal levels suggests that the most important factor was probably the disturbance to family life. The post-war marriage rate increased significantly, from 7.5 per 1,000 population in 1942 to $9 \cdot 8$ in 1943 and $1944 .^{18}$

\section{PERINATAL AND INFANT MORTALITY}

The ten years prior to the war had seen a slight gradual drop in the infant mortality rate from $260 \cdot 81$ per 1,000 live births in 1926 , to 224.83 in 1938 (table 2). The reasons

${ }^{17}$ Report . . . 1941, op. cit., note 13 above, pp. 2, 5. Also see S. Dobbie, Grace under Malta, London, Lindsay Drummond, 1944, p. 75 regarding conscription conditions for Maltese.

18 Annual reports . . 1936-1952, op. cit., note 16 above. 


\section{Reproductive performance on the Maltese Islands}

for this decline were various but the organization of infant health care services of the time contributed to it. The main cause of death in the infant aged under one year appears to have been diarrhoeal disease, in whose prevention and management social circumstances play an important role. The specific mortality rate from diarrhoeal disease in infants aged less than one year was $151 \cdot 1$ per 1,000 live births in 1926, and 130.1 in 1938 (figure 2). Infant health care was based on two complementary systems. The government-organized service was based on the work of District Nurses spread over 16 regions on Malta and Gozo. These nurses visited homes where births occurred and worked in close association with the District Medical Officers. They helped, among other things, to keep in check the neonatal mortality rate to a level of 44.2 per 1,000 live births for the period 1937-39. In addition, the government granted money to needy mothers of infants under one year, the rates being fixed by the Commissioners of Charity. The government also contributed to the Mother's and Infant's Health Association which maintained four infant health centres on Malta, and whose volunteer helpers visited newly-confined mothers in the harbour region and its suburbs on Malta. ${ }^{19}$

Table 2: PERINATAL AND INFANT MORTALITY, 1926-48

\begin{tabular}{|c|c|c|c|c|c|c|c|}
\hline \multirow[t]{2}{*}{ Year } & \multirow{2}{*}{$\begin{array}{l}\text { Live } \\
\text { births } \\
\text { No. }\end{array}$} & \multicolumn{2}{|c|}{ Still births } & \multicolumn{2}{|c|}{ Neonatal deaths } & \multicolumn{2}{|c|}{ Infant deaths } \\
\hline & & No. & $\%_{0} \mathrm{~TB}$ & No. & $\%_{0}$ LB & No. & $\%_{0} \mathrm{LB}$ \\
\hline 1926 & 7,485 & 248 & $32 \cdot 1$ & & & 1,953 & $260 \cdot 8$ \\
\hline 1937 & 8,879 & 345 & $37 \cdot 4$ & 380 & $42 \cdot 8$ & 2,155 & $242 \cdot 7$ \\
\hline 1938 & 8,704 & 249 & 27.8 & 398 & $45 \cdot 7$ & 1,957 & $224 \cdot 8$ \\
\hline 1939 & 8,930 & 309 & $33 \cdot 4$ & 393 & 44.0 & 2,027 & $227 \cdot 0$ \\
\hline 1940 & 8,808 & 261 & $28 \cdot 8$ & 395 & $44 \cdot 8$ & 2,434 & $276 \cdot 5$ \\
\hline 1941 & 7,352 & 240 & $31 \cdot 6$ & 341 & $46 \cdot 4$ & 2,231 & $303 \cdot 5$ \\
\hline 1942 & 6,768 & 227 & 32.5 & 316 & $46 \cdot 7$ & 2,336 & $345 \cdot 2$ \\
\hline 1943 & 8,452 & 293 & $33 \cdot 5$ & 336 & 39.8 & 1,775 & 210.0 \\
\hline 1944 & 10,963 & 334 & $29 \cdot 6$ & 435 & $39 \cdot 7$ & 1,275 & $116 \cdot 3$ \\
\hline 1945 & 10,998 & 317 & $28 \cdot 0$ & 437 & $39 \cdot 7$ & 1,584 & $144 \cdot 0$ \\
\hline 1946 & 11,304 & 298 & $25 \cdot 7$ & 517 & $45 \cdot 7$ & 1,478 & $130 \cdot 7$ \\
\hline 1947 & 11,612 & 304 & $25 \cdot 5$ & 441 & 38.0 & 1,397 & $120 \cdot 3$ \\
\hline 1948 & 11,029 & 262 & $23 \cdot 2$ & 416 & $37 \cdot 7$ & 1,246 & 113.0 \\
\hline
\end{tabular}

With the onset of hostilities on Malta, the Department of Health undertook steps to augment the services. The number of District Nurses was increased to 27, the new staff being distributed among those districts which contained the greatest number of shelters and refugees. Besides visits to the newly confined mothers, the nurses made frequent inspection of shelters and refugee centres. The acting Professor of Physiology at the University of Malta, Dr W. Ganado, was detailed for infant welfare work. Besides visiting dormitory shelters and refugee centres frequently, he also instructed mothers on the care of their infants. One or two clinics per week were held in each district. At them, instruction was given to all mothers who attended for the first time, infants were examined, and their mothers advised on their condition and

19 Annual report . . 1938, op. cit., note 1 above, pp. 8-9. 


\section{Savona-Ventura}

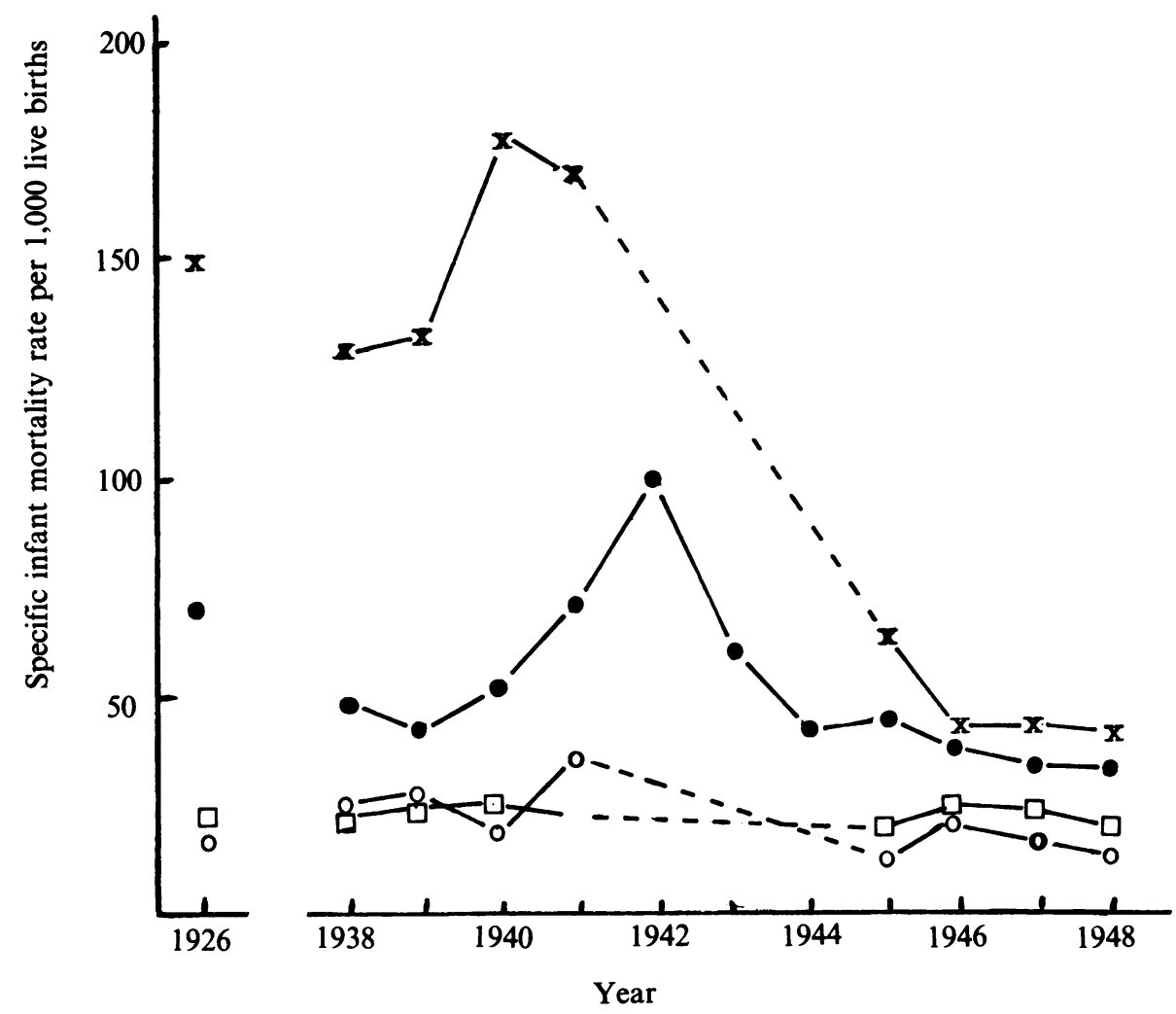

Figure 2: Infant mortality, 1926-48 $\begin{aligned} & \times-\times \text { Enteritis } \bullet-0 \text { Infections }- \text { Congenital debility/prematurity } \\ & 0 \text { Other causes of infant deaths }\end{aligned}$ requirements. An educational campaign, in the form of lectures to mothers, midwives, and District Nurses, and talks on the cable radio system, emphasized the necessity of breast-feeding and its advantages over artificial feeding during war conditions. $^{20}$

In spite of these efforts, infant mortality increased during the first three months of the war, mainly from a greater incidence of diarrhoeal disease, though deaths from congenital debility including prematurity were also higher than in previous years. The latter cause of death contributed to an associated minimal rise in the neonatal mortality rate. Thus the infant mortality rate rose from 227.0 per 1,000 live births in 1939 to 345.2 in 1942 , and the neonatal mortality rate rose from 44.0 per 1,000 live births in 1939 to 46.7 in 1942 (table 2). This rise must be ascribed to the war, when large numbers of families had to live for a greater part of the year under very

${ }^{20}$ Annual report . . . 1940, op. cit., note 12 above, pp. 10-11, 25. 


\section{Reproductive performance on the Maltese Islands}

unhealthy conditions. ${ }^{21}$ The specific death rate from diarrhoeal disease in infants rose from 134.6 per 1,000 live births in 1939 , to 173.2 in 1941 , while the specific death rate from congenital debility also rose, from $48 \cdot 2$ per 1,000 live births in 1938 to 100.6 in 1942 (figure 2).

The cessation of hostilities saw a marked change in the infant mortality rates, with a drop to 210.0 per 1,000 live births in 1943 . The neonatal mortality rate similarly dropped to 39.8 per 1,000 live births in 1943 (table 2). The post-war decline in both infant and neonatal mortality was attributed to a lower incidence of measles, whooping cough, and diphtheria; the employment of sulphonamides in respiratory and intestinal disease; and the intensive work of the health visitors. The main factors, however, were the increasing prosperity of some classes of the population, better nutrition, and the greater care bestowed in general on the requirements of health. In addition, following the increase in marriage rate during the war, a greater proportion of the infant population consisted of first-borns, allowing for better infant care. ${ }^{22}$ The specific infant mortality rate from diarrhoeal disease in 1945 dropped to 63.5 per 1,000 live births, while deaths from congenital debility dropped to $46 \cdot 2$ (figure 2 ).

The bad health conditions and nutrition of the war years appears to have had no significant effect on the still-birth rate (table 2), this being overall lower during the war period 1940-42 (30.8 per cent of total births) than the previous three-year period 1937-39 (32.9 per cent). The rate continued to decline after the war. The decline during the war may be attributed to the greater antenatal attendance rates at the hospital in Malta. The maternity and gynaecological out-patient department saw a total of 552 new maternity and gynaecological cases in 1939, and a total of 1,061 and 2,940 cases respectively in 1941 and 1942 . The relatively high attendance rate persisted in the post-war period: 1,312 and 1,261 new cases were seen during 1943 and $1944 .^{23}$ The increased rate of attendances during the war may have been stimulated by the difficulty of obtaining adequate district medical antenatal care, and possibly also by the allowance of such special rations as tinned or powdered milk, ${ }^{24}$ given to pregnant mothers. The increased hospital-confinement rate could also have contributed towards a decline in the fresh still-birth rates.

\section{MATERNAL MORBIDITY}

In spite of the adverse conditions of the war years, the maternal mortality rate for the period 1940-42 was slightly lower, at $317 \cdot 0$ per 100,000 total births, than it had been in

\footnotetext{
${ }^{21}$ Report . . . 1941, op. cit., note 13 above, p. 1. "Conditions that the war has brought about are emenently conductive [sic] to the deterioration of health and the dissemination of disease. To the overcrowding and communal living, the lack of proper facilities for washing, for preparation of food and for other necessities of life, must be added confinement for long hours in damp, dark and musty underground shelters, noisy and disturbed nights, the strain of ever-present danger, lack of amenities, and monotonous and restricted diet."

${ }_{22}$ Report on the health conditions of the Maltese Islands and on the work of the Medical and Health Department including the Emergency Medical Services for the year 1943, Malta, Govn. Printing Office, 1945 , p. 8.

23 Annual reports . . . 1936-1952, op. cit., note 16 above.

24 Shankland and Hunter, op. cit., note 3 above, p. 54: "Milk ... was unobtainable in Malta, and a strictly limited amount of powdered milk was doled out to invalids, infants under seven years of age and expectant mothers only"; and De Domenico, op. cit., note 2 above, p. 153, reporting the broadcast by the Lt. Governor, Sir E. Jackson, on 20 June 1942: the "use of tinned milk is already restricted to young children and women with child".
} 


\section{Savona-Ventura}

the previous three-year period 1937-39 (383.0 per 100,000). After the war the maternal mortality rate fell significantly, to 190.7 in the period $1943-45$, a trend that was maintained subsequently. The incidence of puerperal sepsis during the war years, surprisingly, decreased markedly from 751.4 per 100,000 total births in 1937-39, to 448.1 in 1940-42 (table 3). This decrease can only be attributed to better supervision of intra-partum care with the higher hospital-confinement rates during these year, and the use of rock-shelter labour rooms in various villages: no cases of sepsis were reported from these. ${ }^{25}$ The mortality rate from puerperal sepsis correspondingly decreased during the war year from 116.7 per 100,000 total births in 1937-39 (case fatality rate 15.5 per cent) to 55.0 in $1940-42$ (case fatality rate 12.3 per cent). The relative similarity in case fatality rates between the pre-war and war years suggests that the most important factor in bringing down the mortality from puerperal sepsis was better intra-partum care with aseptic techniques. With the resumption of district deliveries after the war, the incidence of puerperal sepsis rose again to pre-war levels of 726.7 per 100,000 total births during $1943-45$, to subsequently decrease to 362.0 in 1946-48 (table 3). The mortality from sepsis, on the other hand, decreased further in the post-war years to levels of 36.2 per 100,000 total births in 1943-45 and 25.9 in 1946-48 (case fatality rates $5 \cdot 0$ and $7 \cdot 1$ per cent respectively). This drop suggests the introduction of more effective treatment for the condition.

Table 3: MATERNAL MORTALITY AND MORBIDITY, 1937-51

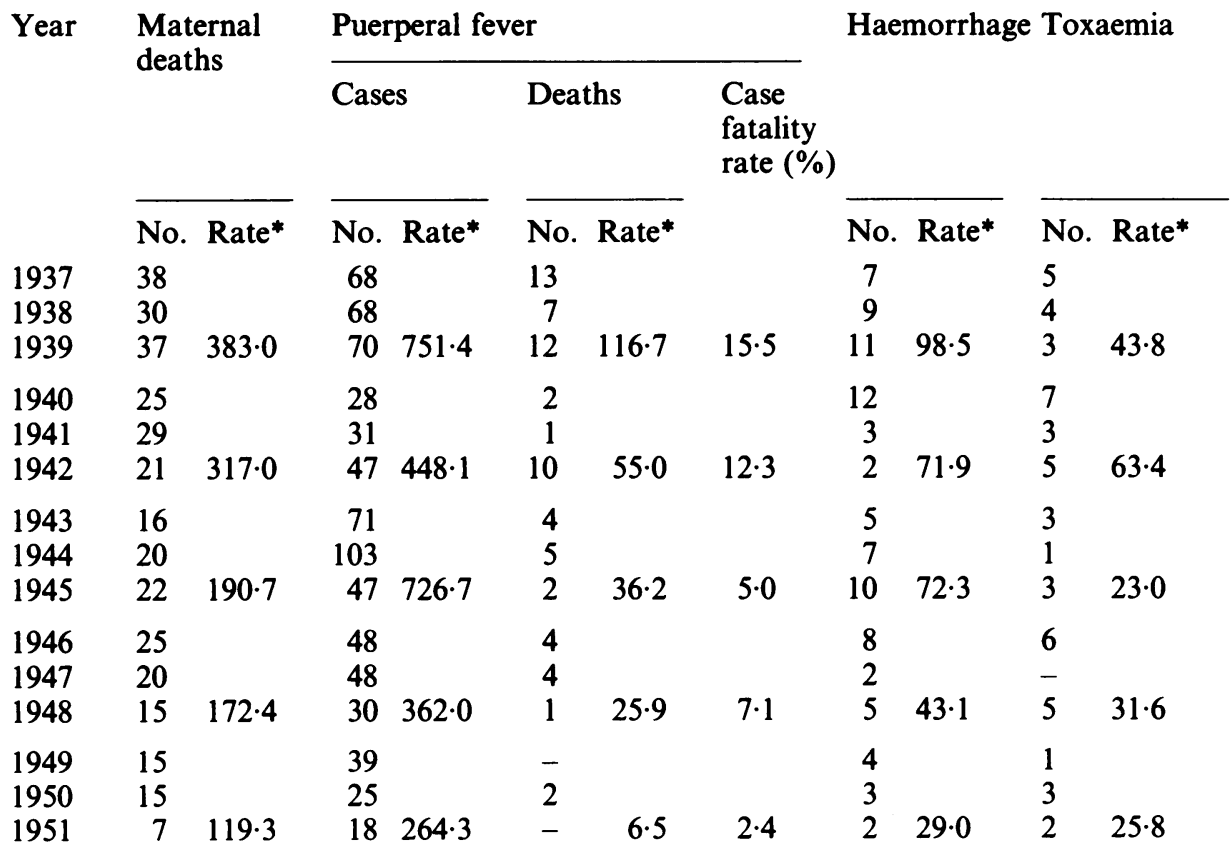

* Rate per 100,000 total births

${ }^{25}$ Report . . 1941, op. cit., note 13 above, p. 2. 


\section{Reproductive performance on the Maltese Islands}

In 1937-38, puerperal sepsis was prevented ${ }^{26}$ by placing any cases developing fever or a septic discharge in the Isolation Hospital. In order to minimize the risk of spray infection, all personnel who came in contact with maternity cases were screened periodically for naso-pharyngeal Streptococcus haemolyticus or for an inflamed throat. Staff with either were not allowed to attend maternity cases. A system of using numbered bed-pans for each puerpera was also in force to prevent spread of infection. The introduction of the use of liquid Dettol or Dettol cream together with sterilized gloves for vaginal examinations, had also helped to decrease the incidence of puerperal sepsis in the hospital. The use of sterile gloves was not compulsory and many vaginal examinations by district midwives were performed without them. Established cases of sepsis were managed by intra-uterine injections of flavine in glycerine, the administration of sulphonamides, and the use of anti-gas gangrene serum in selected cases. Sulphanilimide (Prontosil) was first tried in Malta in 1935 with encouraging results in infections caused by haemolytic streptococcus. It did not, however, come into general use until 1937, when it was tried also in the treatment of gonorrhoea and other infections, including puerperal sepsis. Sulphapyridine appeared in 1938-39. ${ }^{27}$ The sulphonamides remained available during the war years. ${ }^{28}$ Penicillin was first administered to civilians on 31 January $1945 .{ }^{29}$

Maternal mortality following haemorrhagic shock caused by ectopic pregnancy, abortion, antepartum and postpartum haemorrhage also fell during the war period. Thus the specific mortality rate fell from 98.5 per 100,000 total births in $1937-39$ to 71.9 in 1940-42 (table 3). There were two reasons for this decline. On the one hand, increased supervision of labour and delivery enabled earlier diagnosis of obstructed labour, preventing uterine rupture. In 1937, Professor Ellul wrote that there were far too many cases of complete rupture of the uterus. This tragic complication, though inevitable in some cases, might be prevented in many others, as in the instances of neglected pendulous abdomen, version without complete anaesthesia, the application of high forceps, forcible extraction of the foetus before complete dilatation of the cervix, and of the abuse of ecbolics, especially pituitrine, before admission to the hospital. Two memoranda on this subject had been circulated to the District Medical Officers. The situation remained similar in 1938. Cases of incomplete abortion were treated by hot vaginal irrigations and pituitrine injections and if this proved unsuccessful, by cleaning the womb and injecting sterilized glycerine with acriflavin into the uterine cavity. Ectopic gestations were managed surgically in the presence of marked collapse, while other, less acute cases were treated medically and kept under observation. Cases of antepartum haemorrhage from placenta praevia were managed

\footnotetext{
${ }^{26}$ Annual report on the health conditions of the Maltese Islands and on the work of the Medical and Health Department for the year 1937, Malta, Govn. Printing Office, 1938, pp. 119-21; and Annual report ... 1938, op. cit., note 1 above, pp. 106-9.

${ }_{27}$ P. Cassar, 'Clinical teaching in Malta fifty years ago', Medi-scope, 1987, 11: 27.

28 The sulphonamides were definitely available during 1940 and appear to have been widely used. There is no specific mention of these drugs being in short supply during $1941-42$ (see note 8 , above). However, the annual case fatality rate for 1942 rose to 21.3 per cent from $7 \cdot 1$ per cent in 1940 and 2.9 per cent in 1941 , the majority of deaths (8 out of 10) occurring in the March-May period. These statistics suggest that effective treatment may have been short during this period.

${ }^{29}$ P. Cassar, 'Professor Peter Paul Debono: the man and his times', St. Luke's Hospital Gaz., 1975, 11(2): 134
} 


\section{Savona-Ventura}

by classical tamponage when the cervix was closed. Caesarean section was performed in certain primipara with a closed cervix and severe haemorrhage when there was an interest in saving the baby's life. In lateral and marginal cases, rupture of the membranes was performed and a pressure bandage applied over the abdomen. When the bleeding continued, the pulling down of a leg with a 2-pound weight or the use of a Willet's forceps on the caput were occasionally used. Postpartum haemorrhage resulting from atony of the uterus was managed by injections of pituitrine and ergot, together with manual compression of the aorta. Very hot douches in the vagina and occasionally in the uterus were often efficacious. Cases of retained placenta were first treated by the Crede's method, and, if this failed, sterilized water was injected into the umbilical vein. Manual removal under general anaesthetic was performed as a last resort. ${ }^{30}$

Besides the greater supervision of pregnancy and labour during the war years, a more important factor in reducing the specific mortality rate from haemorrhage was the easier availability of blood for transfusion. In 1939, a scheme to make blood available was proposed, but it failed for lack of donors: students occasionally gave blood, but in most cases the patient's relatives were reluctant. ${ }^{31}$ At the beginning of the war in 1940, a blood bank was established in view of the expected casualties. In addition dried blood plasma was made available. ${ }^{32}$

Unlike the trends in maternal deaths from puerperal sepsis and haemorrhage, the specific mortality rate from hypertensive disorders rose during the war years from a level of 43.8 per 100,000 total births in 1937-39 to 63.4 in 1940-42. The rate fell again in the post-war years (table 3). A decrease in the incidence of eclampsia and pre-eclampsia during the Second World War has been reported for Germany, The Netherlands, and Greece, while no change in incidence was found in Vienna and Norway. An increased rate of eclampsia was reported in Budapest and Czechoslovakia. The reports of the increased incidence or no change in the incidence seem to be as authentic as the reports of decrease, but none of these reports took account of the changing patterns of reproduction during wartime with a fall in birth rate and a change in parity. The evidence is inadequate and no clear conclusion can be arrived at regarding the influence of war on the incidence of pre-eclampsia. ${ }^{33}$ The mortality rate from eclampsia in Britain showed little change during the war years, except for a slight drop in 1940. The specific mortality rate fell significantly after $1943 .{ }^{34}$

In the Maltese Islands during 1937 Tweedy's treatment was adopted for severe cases of hypertension, including venesection, luminal, calcium, and acceleration of labour. Marked improvements in the specific mortality rate from hypertensive disease of pregnancy were only made after the introduction of antihypertensive drugs, and

\footnotetext{
30 Annual report . . 1937, op. cit., note 26 above, pp. 119-21; and Annual report . . 1938, op. cit., note 1 above, pp. 106-9.

31 Ibid.

32 Annual report . . 1940, op. cit., note 12 above, p. 28.

33 I. MacGillivray, Pre-eclampsia. The hypertensive disease of pregnancy, London, W. B. Saunders, 1983, pp. 34-5.

34 J. M. M. Kerr, R. W. Johnstone, and M. H. Phillips, Historical review of British obstetrics and gynaecology 1800-1950, Edinburgh, Livingstone, 1954, p. 155.
} 


\section{Reproductive performance on the Maltese Islands}

adequate methods of inducing labour. The post-war fall in the specific mortality rate from hypertensive disease in pregnancy occurred at a rate much slower than those of other causes of maternal deaths. ${ }^{35}$ Cases of albuminuria were managed by bed rest, strict dieting, and proper nursing. Induction of labour was resorted to in nonremitting cases. Induction of labour using Watson's method reportedly failed in more than half of the cases; tube induction was very often required. This involved the insertion of three tubes between the membranes and the uterine wall after instrumental dilatation of the cervix. The cervix was packed with flavin gauze which was changed after $36-48$ hours. This method hardly ever failed. ${ }^{36}$

Most maternal deaths (over 68 per cent) during the war years took place in the hospitals on Malta and Gozo. Cini Hospital on Malta accounted for a total of 36 maternal deaths from the following causes: eclampsia (4), hepatic toxaemia (2), ruptured uterus (6), puerperal sepsis (2), post-abortion sepsis (1), cardiorenal insufficiency (1), uraemia (1), heart disease (1), diabetes (1), pelvic deformity (1), prolonged labour (1), placenta praevia (1), and molar pregnancy (1). The causes of the 13 maternal deaths occurring in Cini Hospital during 1940 were not specified. The Central Hospital and the Isolation Hospital on Malta accounted in 1941-42 for 2 and 7 cases respectively. The deaths at the Central Hospital resulted from eclampsia (1) and "other accidents of childbirth" (1), while the seven deaths at the Isolation Hospital all resulted from post-abortion sepsis. No data are available as to number and causes of deaths in these hospitals in 1940. Victoria Hospital in Gozo accounted for six deaths during 1940-42 from eclampsia (1), puerperal haemorrhage (1), other accidents of childbirth (2) and unspecified (2). ${ }^{37}$

The Second World War in Malta brought on marked epidemiological changes. The disturbance caused to family life from the direct and indirect effects of the war activity resulted in a marked decrease in the reproductive efficiency of the Maltese population resulting in a marked decrease in the birth rate, in spite of an increase in the marriage rate. The disturbance to normal life changed attitudes towards obstetric care: more patients attended antenatal clinics at the hospital's out-patients department and approximately twice as many patients delivered in the hospital in Malta. The figures returned to pre-war levels after the cessation of hostilities, but wartime experience may have ultimately stimulated the continuing trend towards hospital delivery which started in the 1950s. In 1955 it was noted that, whereas formerly mothers looked at maternity services with indifference, sometimes even with diffidence, they had started to avail themselves of it very willingly and enjoy its benefits. ${ }^{38}$ In spite of the efforts of the Department of Health to accelerate maternal and child health services, the infant and neonatal mortality rates increased significantly during the war years mainly from diarrhoeal diseases and congenital debility, diseases whose epidemiologies are

\footnotetext{
${ }^{35}$ C. Savona-Ventura and E. S. Grech, 'Maternal mortality in the Maltese Islands', Int. J. Gynaecol. Obstet., 1987, 25: 283-90.

${ }^{36}$ Annual report . . 1937, op. cit., note 26 above, pp. 119-21, and Annual report . . 1938, op. cit., note 1 above, p. 106-9.

37 Annual reports . . 1936-1952, op. cit., note 16 above.

${ }^{38}$ Report on the health conditions of the Maltese Islands and on the work of the Medical and Health Department for the year 1955, Malta, Govn. Printing Office, 1956, p. 6.
} 


\section{Savona-Ventura}

significantly influenced by social factors. The maternal mortality figures show a decrease during the war years, reflecting better supervised intra-partum care and the facilities made available by the re-organization of the health services.

Changes in reproductive performance during the war years are not unique to the Maltese Islands. The medical and nutritional restrictions resulting from the blockade produced a situation similar to that in the occupied Netherlands, where severe dietary deprivation amounted to starvation in 1944-45. The birth rate during the war years fell significantly in most European countries. In the United Kingdom the birth rate dropped to its lowest point during 1940-41 despite an increase in marriages during 1939-40, and then rose sharply to reach a peak in 1947, after which the rate declined to pre-war levels by 1955-56. The perinatal mortality rates in England and Wales fell sharply during the war despite the disruption to life style it caused. This has been ascribed to the practical disappearance of severe forms of poverty resulting from a decline in unemployment, together with an enlightened national food policy which gave special allowances to pregnant women, improving maternal nutrition. The emergency re-organization of maternity health services affected only a minority of women. The infant mortality rate in England and Wales rose minimally from pre-war levels of 50.6 per 1,000 live births in 1939 , to 60.0 in $1941 .{ }^{39}$ In The Netherlands the birth rate rose minimally during the war years, with a marked peak in the immediate post-war years. The perinatal mortality rate dropped during the war years, mainly as a result of a drop in the stillbirth rate, the early neonatal mortality rate maintaining a steady trend. The late neonatal death rates exhibited a slight rise in 1945, but a marked rise occurred in the infant mortality rate from about 30 per 1,000 live births in 1939 to nearly 80 in 1945, returning to pre-war levels by 1947 . A similar though less marked rise in infant mortality rates was reported from Belgium, while Sweden reported a drop in infant mortality during the war. ${ }^{40}$ In the United States between 1935 and 1945 the infant mortality rate declined at a fairly rapid rate ( 4.5 per cent), and this was followed by even greater reductions in the immediate post-war period. The decline was more marked in the post-neonatal mortality. ${ }^{41}$ The maternal mortality rate in Britain, as well as in the United States, Sweden, Australia and New Zealand, continued to fall without interruption throughout the war. It is probable that the sulphonamides were the most important factor in this decline, although other reasons played their part. In occupied France, The Netherlands, and Belgium, the fall in maternal mortality rate which started in the decade before the war was temporarily interrupted. The reasons for this may have included reduced availability of antiseptics and sulphonamides, a partial or complete absence of obstetric care for women who were in hiding from the occupying forces or in prison, and in some countries, such as The Netherlands during $1944-45$, food shortages verging on starvation. ${ }^{42}$

\footnotetext{
${ }^{39}$ N. R. Butler and E. D. Alberman, Perinatal problems: the 2nd report of the 1958 British Perinatal Mortality Survey, Edinburgh, Livingstone, 1969, pp. 4-7; and Kerry, op. cit., note 34 above, pp. 282-93.

$40 \mathrm{~W}$. H. Stewart and W. J. Cohen, Infant loss in the Netherlands, Washington, National Center for Health Statistics, 1968, pp. 9-10.

${ }^{41}$ S. Shapiro, E. P. Schlesinger, and R. E. L. Nesbitt, Infant, perinatal, maternal and childhood mortality in the United States, Cambridge, Mass., Harvard Univ. Press, 1968, pp. 145-6, 7.

${ }^{42}$ I. Loudon, 'Maternal mortality: 1880-1950. Some regional and international comparisons', Soc. Hist. Med., 1988, 1(2): 183-228.
} 
Deaths from medical causes during the war must be considered "sick war casualties", since the adverse health conditions of these years contributed to these deaths. The hardships suffered by pregnant women during the war were well evoked by De Domenico when he wrote,

In his own sphere the civilian has earned His Majesty's reward [the George Cross] just as much as any fighting man ... If any one section is to be singled out let it be the Women of Malta. Under the most trying circumstances the housewife maintained an unbroken service to her menfolk ... She it was who bore sons to Malta, despite the incessant din of battle, carrying her unborn burden up and down the stiff shelter staircase-perhaps as often as ten times daily. She it was who bore without complaint the revolting atmosphere of the undergrounds, when in her plight any scent and every smell should have sickened her. She it was, who when her time came, laboured whilst death rained from the skies, and when the child's ears first heard the roar of battle, her thought was for his safety. She but glanced at the infant and begged that he be taken to shelter. ${ }^{43}$

${ }^{43}$ De Domenico, op. cit., note 2 above, pp. 131-2. The George Cross was awarded to the Maltese population by King George VI on 15 April 1942. 